\title{
BMJ Open Guideline recommendations and antimicrobial resistance: the need for a change
}

\author{
Christelle Elias, ${ }^{1}$ Lorenzo Moja, ${ }^{1}$ Dominik Mertz, ${ }^{2}$ Mark Loeb, ${ }^{2}$ Gilles Forte, ${ }^{1}$ \\ Nicola Magrini ${ }^{1}$
}

To cite: Elias C, Moja L, Mertz D, et al. Guideline recommendations and antimicrobial resistance: the need for a change. BMJ Open 2017;7:e016264. doi:10.1136/ bmjopen-2017-016264

- Prepublication history and additional material for this paper are available online. To view these files please visit the journal online (http://dx.doi. org/10.1136/bmjopen-2017016264).

Received 3 February 2017 Revised 13 April 2017 Accepted 21 April 2017

CrossMark

${ }^{1}$ Essential Medicines and Health Products, WHO, Geneva, Switzerland

${ }^{2}$ Medicine, McMaster University, Hamilton, Canada

Correspondence to

Dr. Lorenzo Moja;

mojal@who.int

\section{ABSTRACT}

Objectives Antimicrobial resistance has become a global burden for which inappropriate antimicrobial use is an important contributing factor. Any decisions on the selection of antibiotics use should consider their effects on antimicrobial resistance. The objective of this study was to assess the extent to which antibiotic prescribing guidelines have considered resistance patterns when making recommendations for five highly prevalent infectious syndromes.

Design We used Medline searches complemented with extensive use of Web engine to identify guidelines on empirical treatment of community-acquired pneumonia, urinary tract infections, acute otitis media, rhinosinusitis and pharyngitis. We collected data on microbiology and resistance patterns and identified discrete pattern categories. We assessed the extent to which recommendations considered resistance, in addition to efficacy and safety, when recommending antibiotics.

Results We identified 135 guidelines, which reported a total of 251 recommendations. Most (103/135, 79\%) were from developed countries. Community-acquired pneumonia was the syndrome mostly represented ( 51 , $39 \%)$. In only $16(6.4 \%)$ recommendations, selection of empirical antibiotic was discussed in relation to resistance and specific microbiological data. In a further 69 (27.5\%) recommendations, references were made in relation to resistance, but the attempt was inconsistent. Across syndromes, 12 patterns of resistance with implications on recommendations were observed. $50 \%$ to $75 \%$ of recommendations did not attempt to set recommendation in the context of these patterns.

Conclusion There is consistent evidence that guidelines on empirical antibiotic use did not routinely consider resistance in their recommendations. Decision-makers should analyse and report the extent of local resistance patterns to allow better decision-making.

\section{BACKGROUND}

The appropriate use of antibiotics has become a worldwide priority. In 2000, globally it was estimated 54 billion standard units of antibiotics have been consumed, and this figure increased by $36 \%$ in the following 10 years, creating the preconditions of a public health crisis. ${ }^{12}$ This problem is not confined

\section{Strength and limitations of this study}

As part of the WHO Global Action Plan on Antimicrobial Resistance, this study is an innovative comparison of guidelines on the appropriate use of antibiotics based on resistance patterns across countries.

- Research was limited only to an electronic screening so printed versions of clinical practice guidelines may have been missed.

> Recommendations were arbitrarily hierarchised according to the influence of resistance data collected.

- Further research on the quality and relevance of specific recommendations based on resistance is needed identifying further obstacles to progress antimicrobial resistance and bringing them to light.

to high and middle-income countries where antibiotics are considered as an undeniable right, but it is also accentuated in low-income countries where antibiotics are becoming part of a consumerist approach to healthcare; for example, the use of antibiotics is fourfold in India than in Scandinavian countries. ${ }^{3} 4$ Inappropriate prescribing, over-the-counter sales of antibiotics and high consumption contributed to an increase in bacterial selection pressure. Time trend analyses have reported an increase in antimicrobial resistance (AMR) including extended spectrum beta-lactamase, Gram-negative bacteria resistant to carbapenems or plasmid-mediated colistin resistance. ${ }^{5}$ Such resistance patterns have been associated with negative outlooks on clinical and public health burden, including deaths, attributable to AMR. ${ }^{6}$

In the last 20 years, there has been an emphasis on the need to modify prescribers' behaviours: guidelines emerged as an intervention to support clinical decision-making through a consensual process based on evidence and reinforce collective action to tackle relevant disease problems. ${ }^{7}$ The adoption of guidelines targeting antibiotic prescribing, a medical behaviour 
characterised by scarce diligence, has been associated with large benefits, encompassing both improvement in mortality ${ }^{8}$ and in resistance. ${ }^{9}$ Conscious-scientific societies can contribute to control AMR by producing necessary, appropriate and specific recommendations to optimise the use of antibiotics and inviting health professionals to adhere to them.

We hypothesised that scientific societies and professional associations invested time and energies finalising guidelines to provide information on empirical antibiotic use. We assumed that these guidelines have at the core resistance threats and report information on country-specific resistance patterns, as these are essential information to guide the empirical choice of antibiotics. Therefore, we mapped guidelines targeting five common infectious conditions where empirical therapy prevails and evaluated what proportion of recommendations consider resistance patterns as a driver of the clinical decision-making, how resistance influences recommendations and whether resistance can be better incorporated.

\section{METHODS}

This study is part of a large comprehensive review of antibiotics that aims to revise the selection of antibiotics included in the 2017 WHO Model List of Essential Medicines, and is part of the 2015 Global Action Plan on Antimicrobial Resistance, ${ }^{10}$ a series of international actions to monitor and control antibiotics resistances.

\section{Identification of guidelines}

A guideline was eligible for inclusion if the publication type was a clinical practice guideline (CPG) consistent with the standard definition-'statements that include recommendations intended to optimize patient care that are informed by a systematic review of evidence and an assessment of the benefits and harms of alternative care options'. ${ }^{11}$

A systematic search for CPGs of antibiotic therapy for five infectious disease syndromes-community-acquired pneumonia (CAP), urinary tract infections (UTIs), acute otitis media (AOM), rhinosinusitis (RHI) and pharyngitis (PHA) - was conducted. We selected these diseases as a purposive sample of 23 syndromes considered in the comprehensive Essential Medicine List review. They represent the most prevalent infectious diseases worldwide, a balanced case mix of benign and severe diseases and cover the spectrum of empirical antibiotic treatment choices.

To our knowledge, there is no single repository of CPGs on antibiotics. Therefore, to retrieve relevant CPGs, we first performed a Medline search using the following terms 'clinical practice guideline*' or 'guideline*' in the title combined with the name of the syndrome as key words. For instance, looking at community-acquired pneumonia guidelines, we searched for 'pneumonia' or 'community acquired pneumonia' or 'respiratory tract infection' or 'lower respiratory tract infection'. Second, we used
Google as the search engine to explore documents that are not reported in the medical literature but available on the internet assuming that a relevant number of guidelines would have been possibly published by scientific societies or governmental agencies and released on the internet but not captured by Medline or formal literature repositories. All searches were made using country-specific or local Google versions. ${ }^{12}$ So, for instance, French guidelines were searched on the local version of the Google page-Google.fr. For each website of a potential CPG issuer (eg, scientific society), one reviewer retrieved CPGs through an analysis of the official website. We finally searched the WHO Essential Medicines and Health Products Information Portal, ${ }^{13}$ an online repository of full-text publications on medicines and health products related to WHO priorities, other United Nations (UN) partners, global non-governmental organisations, development agencies and their partners, countries and academics. Resources within the portal were filtered with the help of the WHO information specialist in charge of organising the portal information.

Our searches were conducted during the period JuneJuly 2016. No date, language or age restrictions were applied.

Systematic reviews, meta-analyses as well as consensus conferences were excluded. Duplicated and guidelines superseded by more recent version were also removed.

\section{Information sought for each guideline}

For each included guideline, we sought general information about the country of origin, its income and geographical place according to the WHO regions, infectious syndrome, year of publication, target population, promoting institution and financial support.

\section{Influence of resistance patterns over recommendations}

To be included in the descriptive analysis, a CPG had to provide recommendations on the empirical use of antibiotic treatments for at least one syndrome. We used the standard definition of recommendation of the WHO. That implies a choice between different interventions-antibiotics in the actual study - that have an impact on health and that have implications for the use of resources. ${ }^{14}$

It is important to notice that each CPG can present recommendations across multiple syndromes. We considered each recommendation on antibiotic use as a potential opportunity to incorporate resistance pattern information (ie, desirable criterion). We assumed that patterns should be included in any recommendations about optimal use of antibiotics, the most conservative scenario being that a recommendation clearly excludes relevant resistance, and then recommends preferred antibiotic choice with a curative intent, considering avoidance of further development or spread of resistance. An example is recommending first-line antibiotic therapy amoxicillin or amoxicillin with clavulanate (alternative) for otitis media. Complex scenarios would consider, for instance, the recommendation of alternative antibiotics based on resistance thresholds. 
Table 1 Hierarchy of the recommendations

\section{Level of satisfaction \\ of recommendations}

Satisfactory

Partial satisfactory

\section{Empiric antibiotic}

recommendation was supported

by inconsistent resistance

patterns.

Unsatisfactory
recommendation did not support
any resistance patterns or was
not justified by country-specific
resistance patterns.

\section{Illustration}

Management for uncomplicated cystitis in women in Sweden listed recommendations for preferred antibiotics. For instance, nitrofurantoin was a preferred option as a first-line treatment because of low resistance rates in a community setting, whereas fluoroquinolones were not indicated in this syndrome due to rapidly increasing resistance development. ${ }^{30}$

American recommendations for bacterial rhinosinusitis recommend high-dose amoxicillin as a preferred option over standard-dose amoxicillin primarily to cover and control PRSP. ${ }^{17}$

Filipino recommendations for mild CAP recommended the use of a beta-lactam with a beta-lactamase inhibitor without any justification on resistance. However, macrolides were considered as an alternative treatment because of a high threshold of resistance (20\% resistance rate) among population. ${ }^{31}$

Beta-lactams as well as macrolides were recommended for the management of pharyngitis in Namibia without any specification about microbiology or resistance. ${ }^{32}$

CAP, community-acquired pneumonia; PRSP, penicillin resistant Streptococcus pneumoniae.

Recommendations were classified according to the influence of epidemiological and resistance patterns data on recommendations in three ordinal categories: satisfactory, partial satisfactory and unsatisfactory (table 1). They were considered as satisfactory if they provided a list of empirical antibiotics modulated by complete and country-level collected data on microbiological and resistance patterns. In fact, we arbitrarily postulated that recommendations about optimal antibiotic use should consider country-specific resistance patterns as a key driver of the selection of antibiotic. Resistance patterns had to be consistently reported across recommendations targeting antibiotic use for a syndrome. Partially satisfactory recommendations had some but not all of the resistance pattern information or used this information inconsistently across recommendations. Lastly, recommendations were classified as unsatisfactory when: they did not use epidemiological and resistance data to justify antibiotic selection, recommendations were delinked from resistance patterns or these were not country specific.

For each guideline, one reviewer retrieved information through an analysis of the document. The same reviewer also classified the satisfactory level based on the completeness of resistance patterns information. Different patterns were collegially discussed and doubts were resolved .

For each infectious syndrome, we identified discrete characteristics of resistance with implications on recommendations. In other words, if a recommendation contained data on resistance, it could generate guidance based on such resistance patterns, suggesting appropriate or inappropriate antibiotics (eg, using a specific antibiotic such as amoxicillin-clavulanate in case of risk of bacterial strains producing beta-lactamase in mild CAP). We then calculated how many recommendations failed to consider discrete patterns, reporting median and IQR as measures of distribution.

\section{RESULTS}

We retrieved 148 CPGs: 21 (14\%) from Medline, 97 (66\%) from websites of specialty societies and 30 (20\%) from the WHO Essential Medicines and Health Products Information Portal. Of these CPGs, 135 (91\%) met our inclusion criteria and were described in details, and provided sufficient information for qualitative evaluation. Thirteen guidelines were excluded because no recommendation on empirical treatment was made or were duplicates or out-of-validity guidelines (figure 1).

General characteristics of the guidelines are summarised in table 2. Among the 194 UN member states, $70(36 \%)$ provided guidelines of at least one of the five syndromes. The majority $(106,79 \%)$ of the CPGs arose from high and upper middle-income countries, whereas lower middle and low-income countries contributed marginally $(28,21 \%)$. European Regional Office and Pan American Regional Office were the two most represented WHO regions, originating 44 $(33 \%)$ and $39(29 \%)$ CPGs, respectively. Among the five infectious syndromes studied, CAP's treatment was the top-ranked syndrome in the agenda (51, 39\%), followed by UTI $(42,31 \%)$. Half of the CPGs were published between 2011 and 2016. Figure 2 shows the geographical distribution of guidelines across the 194 UN member states. 


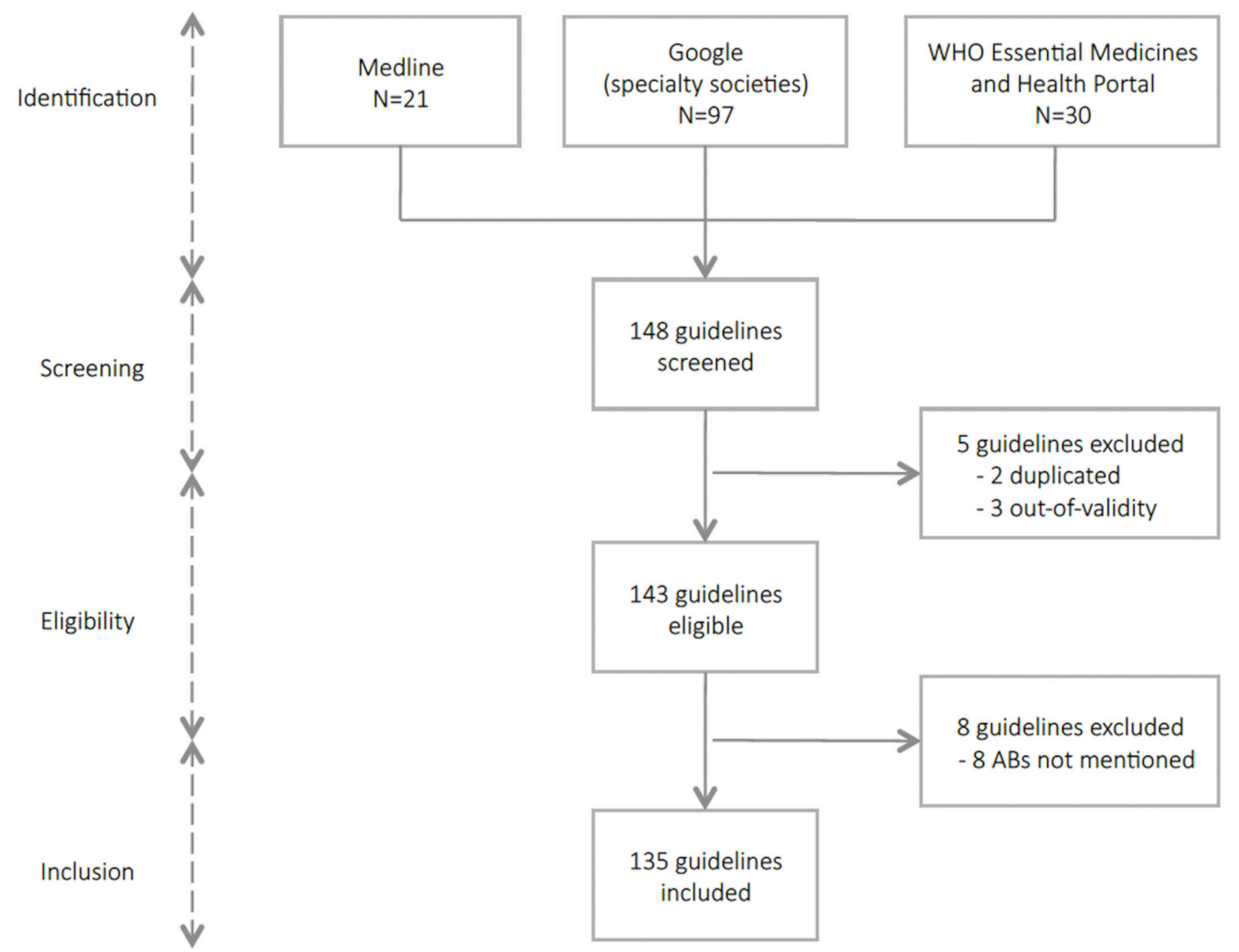

Figure 1 Flow chart of clinical practice guideline. AB, antibiotic.

A total of 251 recommendations were identified: these subgrouped by syndromes will be considered the denominators in the following analyses.

Compliance with our desirable criteria is presented in table 3 . Only a minority of the recommendations -16 $(6.4 \%)$-was classified as satisfactory (ie, including or mentioning resistance), whereas $69(27.5 \%)$ and 166 $(66.1 \%)$ recommendations partially or totally omitted data on microbiological resistance, respectively. Guidelines that incorporated resistance on all recommendations originated from France, ${ }^{15}$ Sweden $^{16}$ and the USA. ${ }^{1718}$

Descriptive analysis of the resistance patterns is shown in table 4 . Of the 12 discrete patterns how resistance may influence recommendations, 10 patterns were identified for CAP, 6 for UTI, 7 for rhinosinusitis and acute otitis media and finally 4 for pharyngitis. Looking at the distribution of resistance into recommendations, $50 \%$ to $75 \%$ of recommendations failed to mention resistance patterns in the antibiotic guidance when these patterns might have had an impact.

For CAP, the risk for atypical pathogens was addressed in $26 \%$ of the recommendations. Multidrug resistance concerns, however, were covered only in $1.4 \%$ of recommendations. Resistance patterns in UTI recommendations ranged from two to five, and nine (14.3\%) UTI recommendations described alternative antibiotics based on resistance threshold.

No satisfactory recommendation was identified for the management of pharyngitis. Resistance is rare in the most common pathogens for bacterial pharyngitis, thus, only one resistance pattern by pharyngitis' recommendations was found.

For all syndromes antibiotics used as an alternative were often mentioned. Fluoroquinolones appeared to be the most frequent alternative antibiotic in CAP $(11 \%)$ and UTIs (12.7\%) (see online supplementary tables 1 and 2). Detailed alternative antibiotics and resistance patterns in acute otitis media, rhinosinusitis and pharyngitis are referenced in online supplementary tables 3, 4 and 5 .

\section{DISCUSSION}

In view of the postantibiotic era and the global burden of antibiotic resistance worldwide, it is important that recommendations consider (in)appropriate antibiotics when there is an opportunity to reduce resistance. This review found an important gap in antibiotics guidelines: resistance patterns were not considered by two-thirds of recommendations for five highly prevalent infectious syndromes. Moreover, of the 251 recommendations, fewer than 1 in 10 consistently reported data on their country-specific resistance patterns. The recommendation would serve better the medical community if a specific antibiotic is preferred over the others, with the aim of providing appropriate coverage and minimising spread and development of resistance. If resistance is not considered in guideline development, it is unlikely to be considered downstream. These data imply that significant changes are needed to the way resistance 


\begin{tabular}{|c|c|c|}
\hline & $\mathbf{n}$ & $\%$ \\
\hline Total & 135 & \\
\hline \multicolumn{3}{|l|}{ Income* } \\
\hline $\mathrm{HIC}$ & 78 & 58 \\
\hline UMIC & 28 & 21 \\
\hline LMIC & 17 & 13 \\
\hline LIC & 11 & 8 \\
\hline \multicolumn{3}{|l|}{ WHO region* } \\
\hline AFRO & 23 & 17 \\
\hline EMRO & 8 & 6 \\
\hline EURO & 44 & 33 \\
\hline РAHO & 39 & 29 \\
\hline SEARO & 3 & 3 \\
\hline WPRO & 16 & 12 \\
\hline \multicolumn{3}{|l|}{ Syndromes } \\
\hline Community acquired pneumonia & 51 & 39 \\
\hline Urinary tract infections & 42 & 31 \\
\hline Acute otitis media & 16 & 12 \\
\hline Rhinosinusitis & 14 & 10 \\
\hline Pharyngitis & 12 & 8 \\
\hline
\end{tabular}

${ }^{*}$ Total of 133, European Union was not part of a WHO region or the World Bank classification. ${ }^{33}$

AFRO, African Regional Office; CPG, clinical practice guidelines; EMRO, Eastern Mediterranean Regional Office; EURO, European Regional Office; HIC, high-income country; LIC, low-income country; LMIC, lower middle-income country; PAHO, Pan American Regional Office; SEARO, South East Asia Regional Office; UMIC, upper middle-income country.

data are considered in recommendations for antibiotics.

Given the scarce attention to resistance, it is not surprising that evidence of substantial inappropriate or overuse of non-first-line antibiotics for most common conditions is prevalent in the medical literature. For instance, data from the USA indicate that the problem of inappropriate antibiotic prescribing includes not only prescriptions that are unnecessary altogether, but also inappropriate selection of agents: physicians prescribed inappropriate antibiotics in about $30 \%$ to $50 \%$ of ambulatory adult consultations with suspected common infectious diseases. ${ }^{19} 20$ However, when guidance is provided, evidence shows a more conscious use of antibiotics. ${ }^{21}$ Since large areas of the world lack the infrastructure to collect resistance data, countries in need should be supported through international projects such as ReAct ${ }^{22}$ or Ecumenical Pharmacy Network. ${ }^{23}$ Guidelines certainly deserve attention, but implementation and quality improvement interventions are also important. Indeed, education and incentives that facilitate antibiotic optimal prescription should also be sustained by adequate policies.
In the move towards better management of resistance, there is room for better standardisation of approaches to include resistance on recommendations and better reporting of resistance data. Panels should scrutinise country-specific resistance data when considering antibiotic recommendations and should report the data, including important time trends. The quality of guidelines is closely intertwined with the quality of reporting. It is possible that guidelines took resistance patterns into consideration in their recommendations without mentioning it. Lack of details on how recommendations were developed leads users to assume that the quality was inadequate, unless information to the contrary is provided. ${ }^{24}$ This is often justified because faulty reporting generally reflects faulty methods. ${ }^{25}$

Although some findings are worrisome, other look more positive. One-third of countries had at least one guideline on antibiotic use: even in the absence of published data, this number suggests that the guideline panels invested a remarkable amount of energy in this field. Fourteen countries produced more than two guidelines for at least one syndrome, raising concerns for duplication of efforts. The more prolific country, Spain, had a production of 13 documents, likely to generate redundancy and confusion. Most guidelines were from high-income countries, with low- and lower middle-income countries providing only $21 \%$. Weak healthcare systems, including inadequate infrastructures for resistance collection, may justify the absence of epidemiological and resistance data in these countries.

Resistance patterns are highly heterogeneous: patterns in upper respiratory tract infections and UTIs are limited in comparison with CAPs. In the latter, antibiotics and resistance may play a substantial role avoiding an evolution into life-threatening diseases. Paucity of resistance data in upper respiratory tract infections can be explained by the high probability of a viral aetiology and a benign disease decourse. Antibiotics are not recommended as treatment by many scientific societies: the National Institute of Health and Care Excellence guidelines (UK) did not include any antibiotic therapy in their guidance for these three syndromes. ${ }^{26}$ This approach converges with the concept of wait-and-see prescription to reduce unnecessary antibiotics use, which demonstrated to be efficient in the treatment of acute otitis media in children. ${ }^{27}$

National and international recommendations should be accompanied by facility-specific antibiotic recommendations, particularly for common syndromes. Among the others, surgical prophylaxis has an important role as target of local stewardship programmes. Most guidelines recommend a maximum postoperative duration of surgical antibiotic prophylaxis of 24 hours, but increasing evidence shows that using only a single preoperative dose (and possible additional intraoperative doses according to the duration of the operation) might be equally effective. ${ }^{28}$ Prophylaxis use should be risk adjusted according to surgical procedures to ensure that harms in terms of bacterial resistance do not outweigh the benefits. 


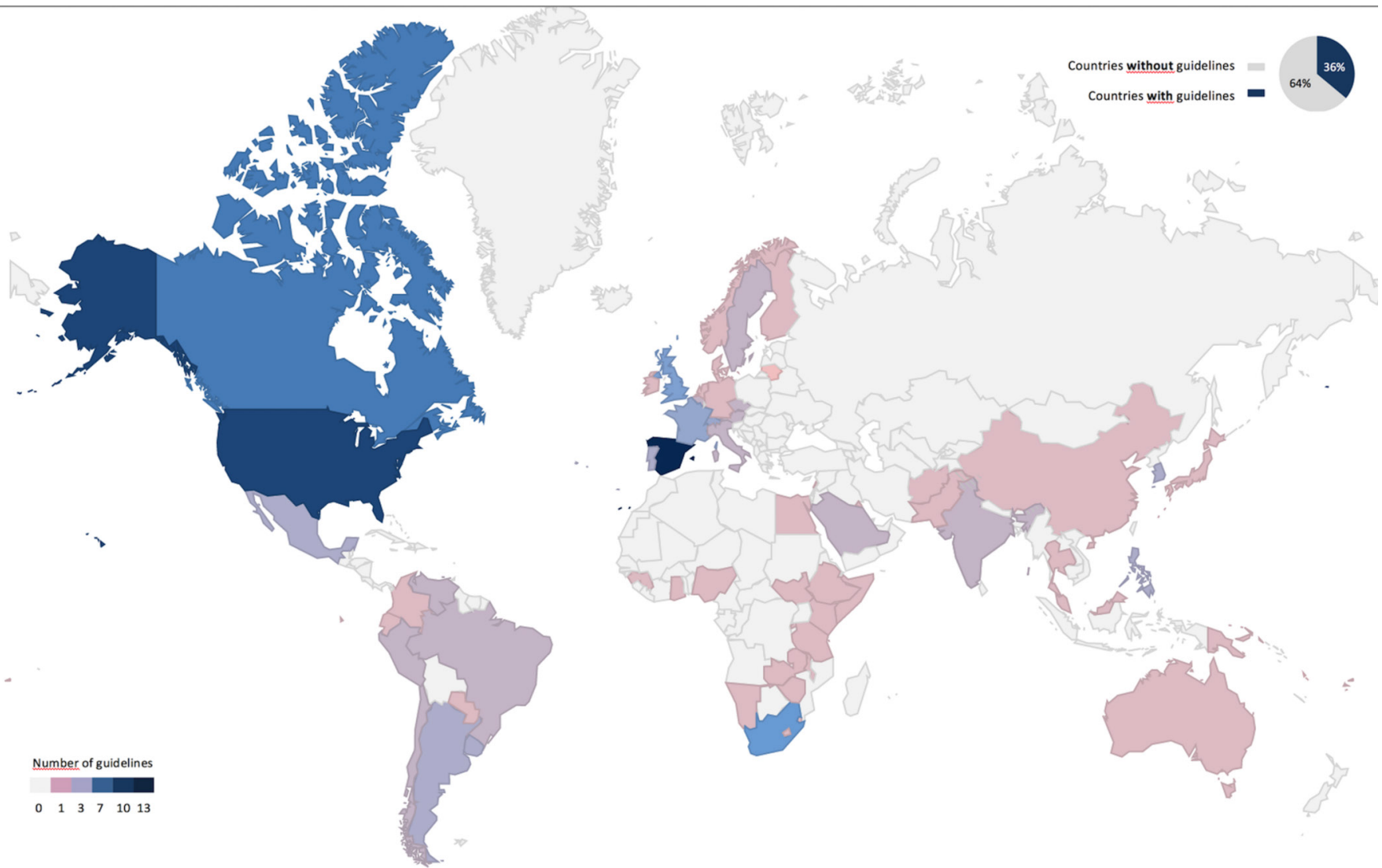

Figure 2 Geographical distribution of clinical practice guidelines $(n=135)$.

Implementation of a monitored antibiotic policies results in lower total antibiotic consumption, reduced antibiotic resistance and reduced costs without increasing the risk of postoperative infections. ${ }^{29}$

We recognise that our study can provide nothing more than a snapshot of the current state of the recommendations related to one dimension, antibiotic resistance. Comprehensive user-centred evaluations of the overall quality of guideline are needed. It was not our aim to assess whether recommendations have improved or worsened over time. Rather we sought to assess whether a problem existed at the time of our study. We did not investigate if recommendations on discrete resistance patterns were correct, or supported by evidence. The relevance of resistance patterns was not weighted. We accepted study authors' guidance on discrete patterns at face value, without further evaluating the quality of the recommendation. We adopted a non-validated arbitrary ordinal scale. Searches were done by a single researcher. We did not consider paper-based guidelines, which might be still prevalent in some contexts. Further research on the quality and relevance of specific recommendations based on resistance is needed identifying further obstacles to progress AMR and bringing them to light.

\section{CONCLUSION}

Our findings revealed that guidelines on empirical use of antibiotics do not provide meaningful information on resistance patterns and interpretation by decision-makers is difficult because-as a principle-local resistance patterns should always be considered with empirical antibiotic choices. In appraising the evidence for antibiotic use guideline, developers should be aware of the breadth and depth of overarching resistance issues. Awareness and understanding of AMR through surveillance and

\begin{tabular}{|c|c|c|c|c|c|c|}
\hline $\begin{array}{l}\text { Hierarchy of } \\
\text { recommendations }\end{array}$ & $\begin{array}{l}\text { CAP, } \\
\text { n (\%) }\end{array}$ & $\begin{array}{l}\text { UTI, } \\
\text { n (\%) }\end{array}$ & $\begin{array}{l}\text { AOM, } \\
\text { n (\%) }\end{array}$ & $\begin{array}{l}\text { RHI, } \\
\text { n (\%) }\end{array}$ & $\begin{array}{l}\text { PHA, } \\
\text { n (\%) }\end{array}$ & $\begin{array}{l}\text { Total, } \\
\text { n (\%) }\end{array}$ \\
\hline Satisfactory & $4(5.5)$ & $5(7.9)$ & $3(7.1)$ & $4(10.2)$ & $0(0)$ & $16(6.4)$ \\
\hline Partial satisfactory & $31(42.5)$ & $11(17.4)$ & $11(26.2)$ & $6(15.4)$ & $10(29.4)$ & $69(27.5)$ \\
\hline Unsatisfactory & 38 (52.0) & $47(74.6)$ & $28(66.7)$ & $29(74.4)$ & 24 (70.6) & $166(66.1)$ \\
\hline Total & 73 & 63 & 42 & 39 & 34 & 251 \\
\hline
\end{tabular}

$\mathrm{AOM}$, acute otitis media; CAP, community acquired pneumonia, $\mathrm{PH}$, pharyngitis; $\mathrm{RH}$, rhinosinusitis; UTI, urinary tract infection. 
Table 4 Descriptive analysis of resistance patterns in the recommendations grouped by syndrome $(n=251)$

\begin{tabular}{|c|c|c|c|c|c|}
\hline & $\begin{array}{l}\text { CAP, } \\
\mathrm{n}(\%)\end{array}$ & $\begin{array}{l}\text { UTI, } \\
\text { n (\%) }\end{array}$ & $\begin{array}{l}\text { AOM, } \\
\text { n (\%) }\end{array}$ & $\begin{array}{l}\text { RHI, } \\
\text { n (\%) }\end{array}$ & $\begin{array}{l}\text { PHA, } \\
\text { n (\%) }\end{array}$ \\
\hline \multicolumn{6}{|l|}{ Recommendations considering resistance patterns } \\
\hline $\begin{array}{l}\text { Antibiotic used as an alternative because of high } \\
\text { resistance rate }\end{array}$ & $14(19.2)$ & $9(14.3)$ & $5(11.9)$ & $3(7.7)$ & $1(2.9)$ \\
\hline Antibiotic not indicated because of high resistance rate & $2(2.7)$ & $6(9.5)$ & $1(2.4)$ & $3(7.7)$ & $5(14.7)$ \\
\hline Resistance risk & $12(16.4)$ & $7(11.1)$ & $4(9.5)$ & $3(7.7)$ & - \\
\hline Resistance threshold & - & $9(14.3)$ & - & $2(5.1)$ & $2(5.9)$ \\
\hline Resistance AB & - & $5(7.9 \%)$ & - & - & - \\
\hline Resistance dosage & $8(11.0)$ & - & $7(16.7)$ & $8(20.5)$ & - \\
\hline Atypical pathogens & $19(26.0)$ & - & - & - & $1(2.9)$ \\
\hline MRSA risk & $7(9.6)$ & - & - & - & _- \\
\hline MDR risk & $1(1.4)$ & $5(7.9)$ & $1(2.4)$ & - & - \\
\hline PRSP risk & $6(8.2)$ & - & $6(14.3)$ & $5(12.8)$ & - \\
\hline Pseudomonas risk & $14(19.2)$ & _ & - & - & - \\
\hline Beta-lactamase risk & $8(11.0)$ & - & $11(26.2)$ & $7(17.9)$ & - \\
\hline \multicolumn{6}{|l|}{$\begin{array}{l}\text { Discrete resistance patterns mentioned in } \\
\text { recommendations }\end{array}$} \\
\hline Total & 10 & 6 & 7 & 7 & 4 \\
\hline $\begin{array}{l}\text { Median } \\
\mathrm{n} \\
(\%)\end{array}$ & $\begin{array}{l}3 \\
(30.0)\end{array}$ & $\begin{array}{l}2 \\
(33.3)\end{array}$ & $\begin{array}{l}2 \\
(28.6)\end{array}$ & $\begin{array}{l}3.5 \\
(50.0)\end{array}$ & $\begin{array}{l}1 \\
(25.0)\end{array}$ \\
\hline $\begin{array}{l}\text { IQR } \\
n \\
(\%)\end{array}$ & $\begin{array}{l}2-3 \\
(20-30)\end{array}$ & $\begin{array}{l}2-5 \\
(33.3-83.3)\end{array}$ & $\begin{array}{l}1.3-3 \\
(17.9-42.9)\end{array}$ & $\begin{array}{l}1.7-4 \\
(21.4-57.1)\end{array}$ & $\begin{array}{l}1-1 \\
(25-25)\end{array}$ \\
\hline
\end{tabular}

AOM, acute otitis media; Atypical pathogens, risk of atypical pathogens; CAP, community acquired pneumonia; MDR risk, risk of multidrug resistant strains; MRSA risk, risk of meticillin-resistant Staphylococcus aureus; PHA, pharyngitis; PRSP risk, risk of penicillin resistant Streptococcus pneumonia; Pseudomonas risk, risk of Pseudomonas aeruginosa; Resistance AB, antibiotic used if first-line AB is resistant; Resistance dosage, antibiotic used at high dosage if there is a risk of resistant strains; Resistance risk, antibiotic used only if there is a risk of increasing resistance (eg, recent use of critical $A B$ during past months); Resistance threshold, antibiotic used only under a certain threshold of resistance; $\mathrm{RHI}$, rhinosinusitis; UTI, urinary tract infection; beta-lactamase risk, risk of strains producing beta-lactamase.

research are pillars of the WHO Global Action Plan on Antimicrobial Resistance. These results can be used by global initiatives such as the UN General Assembly High-Level Meeting on Antimicrobial Resistance and the Conscience of Antimicrobial Resistance Accountability Alliance to monitor progress.

Acknowledgements The authors would like to thank the WHO for coordinating this study and its financial support.

Contributors All authors made a substantial contribution to the conception and the design of the study. CE contributed to literature search and data collection. CE and LM contributed to the analysis and interpretation of data. CE and LM drafted the initial manuscript. NM and GF coordinated the study. CE, LM, DM, ML, GF and NM contributed to the review of the manuscript. All authors read and approved the final manuscript.

Funding The study was funded internally by the Department of Essential Medicines and Health Products of the WHO.

Competing interests None declared.

Provenance and peer review Not commissioned; externally peer reviewed.

Data sharing statement There is no additional unpublished data to share for this original research article.

Open Access This is an Open Access article distributed in accordance with the Creative Commons Attribution Non Commercial (CC BY-NC 4.0) license, which permits others to distribute, remix, adapt, build upon this work non-commercially, and license their derivative works on different terms, provided the original work is properly cited and the use is non-commercial. See: http://creativecommons.org/ licenses/by-nc/4.0/

(C) Article author(s) (or their employer(s) unless otherwise stated in the text of the article) 2017. All rights reserved. No commercial use is permitted unless otherwise expressly granted.

\section{REFERENCES}

1. Laxminarayan R, Matsoso P, Pant $S$, et al. Access to effective antimicrobials: a worldwide challenge. Lancet 2016;387:168-75.

2. Van Boeckel TP, Gandra S, Ashok A, et al. Global antibiotic consumption 2000 to 2010: an analysis of national pharmaceutical sales data. Lancet Infect Dis 2014;14:742-50.

3. ECDC. Summary of the latest data on antibiotic consumption in the European Union. 2015. http://ecdc.europa.eu/en/eaad/documents/ antibiotics-consumption-eu-data-2014.pdf (accessed 1 Feb2017).

4. Kotwani A, Holloway K. Trends in antibiotic use among outpatients in New Delhi, India. BMC Infect Dis 2011;11:99.

5. WHO. Global Report on Surveillance. Bull World Health Organ 2014;61:383-94.

6. O'Neill J. Tackling drug-resistant infections globally: final report and recommendations the review on antimicrobial resistance. 2016.

7. Årdal C, Outterson K, Hoffman SJ, et al. International cooperation to improve access to and sustain effectiveness of antimicrobials. Lancet $2016 ; 387$. 
8. Schuts EC, Hulscher ME, Mouton JW, et al. Current evidence on hospital antimicrobial stewardship objectives: a systematic review and meta-analysis. Lancet Infect Dis 2016;16:847-56.

9. Yusuf E, Ong DS, Martin-Quiros A, et al. A large survey among European trainees in clinical microbiology and infectious disease on training systems and training adequacy: identifying the gaps and suggesting improvements. Eur J Clin Microbiol Infect Dis 2017;36:233-42.

10. WHO. Global action plan on antimicrobial resistance. $2015 ;: 1-4$. http://apps.who.int/gb/ebwha/pdf_files/WHA68/A68_R7-en.pdf (accessed 1 Feb 2017).

11. Graham R, Mancher M, Wolman DM. Clinical practice guidelines we can trust, 2011.

12. Wikipedia. Google domains. https://en.wikipedia.org/wiki/List_of_ Google_domains (accessed 1 Feb 2017)

13. WHO Essential Medicines and Health Products Information Portal. http://apps.who.int/medicinedocs/en/ accessed 1 Feb 2017

14. WHO Guideline Development. http://apps.who.int/iris/bitstream/ 10665/75146/1/9789241548441_eng.pdf (accessed 1 Feb2017).

15. Société de pathologie infectieuse de langue francaise. Diagnostic et antibiothérapie des infections urinaires bactériennes communautaires de l'adulte. 2015:1-43 http://www.infectiologie.com/UserFiles/File/ spilf/recos/infections-urinaires-spilf.pdf ((accessed 1 Feb2017).).

16. Spindler C, Strålin K, Eriksson L, et al. Swedish guidelines on the management of community-acquired pneumonia in immunocompetent adults - Swedish Society of Infectious Diseases 2012. Scand J Infect Dis 2012;44:885-902.

17. Chow AW, Benninger MS, Brook I, et al. IDSA clinical practice guideline for acute bacterial rhinosinusitis in children and adults. Clin Infect Dis 2012;54:1041-5.

18. Lieberthal AS, Carroll AE, Chonmaitree T, et al. The diagnosis and management of acute otitis media. Pediatrics 2013;131:e964-e999.

19. Fleming-Dutra KE, Hersh AL, Shapiro DJ, et al. Prevalence of inappropriate antibiotic prescriptions among US ambulatory care visits, 2010-2011. JAMA 2016;315:1864-73.

20. Hersh AL, Fleming-Dutra KE, Shapiro DJ, et al. Frequency of first-line antibiotic selection among US ambulatory care visits for otitis media, sinusitis, and pharyngitis. JAMA Intern Med 2016;176:1870.

21. Fernández González F, Detrés J, Torrellas P, et al. Comparison of the appropriate use of antibiotics based on clinical guidelines between physicians in-training versus practicing physicians. Bol Asoc Med $P$ $R$ 2013;105:21-4.

22. ReAct. Action on Antibiotic Resistance - ReAct. 2012. http://www. reactgroup.org/ (accessed 1 Feb 2017).

23. Ecumenical Pharmaceutical Network. http://www.epnetwork.org/en/ accessed 1 Feb2017

24. Shaughnessy AF, Cosgrove L, Lexchin JR. The need to systematically evaluate clinical practice guidelines. J Am Board Fam Med 2016;29:644-8.

25. Liberati A, Himel HN, Chalmers TC. A quality assessment of randomized control trials of primary treatment of breast cancer. $J$ Clin Oncol 1986;4:942-51.

26. National Institute for Health and Clinical Excellence. Respiratory tract infections - antibiotic prescribing prescribing of antibiotics for self-limiting respiratory tract infections in adults and children in primary care, 2008.

27. Spiro DM, Tay K-Y, Arnold DH, et al. Wait-and-see prescription for the treatment of acute otitis media. JAMA 2006;296:1235.

28. Allegranzi B, Bischoff $P$, de Jonge $S$, et al. New WHO recommendations on preoperative measures for surgical site infection prevention: an evidence-based global perspective. Lancet Infect Dis 2016;16:e276-e287.

29. Cai T, Verze P, Brugnolli A, et al. Adherence to European Association of Urology guidelines on prophylactic antibiotics: an important step in antimicrobial stewardship. Eur Urol 2016;69:276-83.

30. Infektionsläkarföreningen. Urinvägsinfektioner hos vuxna 2013. http://infektion.net/sites/default/files/VP_UVI_131004.pdf (accessed 1 Feb2017).

31. Phillippine. Philippine clinical practice guidelines on the diagnosis empirical management and prevention of community-acquired pneumonia in immunocompetent adults: 2016 update. http:// philchest.org/v3/wp-content/uploads/2013/05/CAP-Guidelines.pdf (accessed 1 Feb 2017).

32. Republic of Namibia Ministry of Health and Social Services. Namibia Standard treatment guidelines. First Edition, 2011:891. http:// apps.who.int/medicinedocs/documents/s19260en/s19260en.pdf. (accessed 1 Feb 2017).

33. World bank classification. https://datahelpdesk.worldbank.org/ knowledgebase/articles/906519-world-bank-country-and-lendinggroupsaccessed 1 Feb 2017 